\title{
Considerations in Minimally Invasive Surgery for Renal and Ureteric Calculi: A Bicenter Quality Control Study
}

\author{
Saskia Weltings ${ }^{\mathrm{a}} \quad$ Hossain Roshani $^{\mathrm{a}} \quad$ Joost Leenarts $^{\mathrm{b}}$ Rob Pelger ${ }^{\mathrm{c}}$ \\ a Departments of urology, Hagaziekenhuis and ${ }^{\mathrm{b}} \mathrm{MC}$ Haaglanden, The Hague; 'Leiden University Medical Centre, Leiden, Netherlands
}

\author{
Key Words \\ Urolithiasis • Percutaneous nephrolithotomy • \\ Ureterorenoscopy • Minimally invasive surgery
}

\begin{abstract}
Background: The use of minimally invasive surgery is increasing. Evaluating the quality of care brings new sights in the optimization of operating techniques. Methods: We included all procedures performed in two hospitals during 2010 and 2011. A total of 264 patients were included in the ureterorenoscopy (URS) group and 77 patients in the percutaneous nephrolitholapaxy (PCNL) group. Data were gathered by retrospectively reviewing medical records. Results: Mean stone diameter in the URS group was $9 \mathrm{~mm}$. Patients suffered from a single stone in $79 \%$ of the cases. Calculi in the distal ureter, defined as the part of the ureter below the lower border of the sacroiliac joint, were most likely to be removed. A stone-free status was reached in $69 \%$ of the cases using URS. Mean stone diameter in the PCNL group was 23 $\mathrm{mm}$. PCNL was successful in $70 \%$ of the cases in Haga Hospital versus 53\% in Medisch Centrum Haaglanden. Incidence of complications was comparable between the hospitals ( $p$ $=0.5$ ). Outcome and quality of both PCNL and URS was not influenced by sex, age or body mass index. Conclusion: The clinical results were comparable with results in the literature. Further improvement can be made by optimization of technical aspects and centralization of treatment by urologists experienced in minimally invasive techniques.
\end{abstract}

Copyright $\odot 2013$ S. Karger AG, Basel

\section{KARGER}

Fax +4161306 1234

E-Mail karger@karger.ch

www.karger.com
(C) 2013 S. Karger AG, Basel

$1015-9770 / 13 / 0073-0122 \$ 38.00 / 0$

Accessible online at:

www.karger.com/cur

\section{Introduction}

Incidence of stone formation in the urinary tract is increasing. It forms a major global medical problem in different healthcare systems [1]. Urolithiasis may cause severe pain, damage of renal function or even life-threatening septicemia. Extracorporeal shock wave lithotripsy (ESWL), ureterorenoscopy (URS) and percutaneous nephrolitholapaxy (PCNL) are the main treatment modalities for patients suffering from urolithiasis. Minimally invasive therapy for stones in the urinary tract has expanded over the last years, due to better imaging and technical modalities. In clinical practice, semi-rigid or flexible URS is usually applied for stones in the urinary tract when ESWL fails or is contraindicated. Semi-rigid URS is mainly used for distal ureteral stones. Flexible URS is preserved for the more proximal ureteral stones and renal calculi or migrated ureteral stones during semi-rigid procedure. PCNL is the treatment of choice for larger renal calculi $[2,3]$.

The outcome of these procedures varies in the literature, partially depending on the definition of stone-free status, which differs between publications. Social awareness, governmental authorities, insurance companies and patient organizations increasingly demand objective quality controlled data in different fields of medicine, including care in stone disease [4]. Due to these requirements, medical specialists are increasingly starting to work in subspecialties. An effort is made to provide state of the art care by centralization and concentration of par-

Saskia S. Weltings

Departments of urology, Haga Hospital Leyweg 275

NL-2562AA The Hague (Netherlands)

E-Mail saskiaweltings@gmail.com 
Table 1. URS type, operating time, stone removal and postoperative complaints

\begin{tabular}{llll}
\hline & MCH $(\mathrm{n}=68)$ & Haga $(\mathrm{n}=196)$ & Total $(\mathrm{n}=264)$ \\
\hline URS type & & & \\
$\quad$ Semi-rigid & $87 \%(59)$ & $52 \%(102)$ & $61 \%(161)$ \\
$\quad \begin{array}{l}\text { Flexible } \\
\text { Both }\end{array}$ & $6 \%(4)$ & $39 \%(76)$ & $31 \%(80)$ \\
Mean operating time, minutes (range) & $7 \%(5)$ & $9 \%(18)$ & $8 \%(23)$ \\
Stones removed & $35(7-123)$ & $55(11-152)$ & $50(7-152)$ \\
$\quad$ & $63 \%(43)$ & $71 \%(138)$ & $69 \%(181)$ \\
$\quad$ Yes & $34 \%(23)$ & $19 \%(38)$ & $23 \%(61)$ \\
$\quad$ Yes, but with residual fragments & $3 \%(2)$ & $10 \%(20)$ & $8 \%(22)$ \\
Free of complaints & & $72 \%(141)$ & $69 \%(183)$ \\
$\quad$ Yes & $62 \%(42)$ & $25 \%(49)$ & $28.5 \%(75)$ \\
$\quad$ No & $38 \%(26)$ & $3 \%(6)$ & $2.5 \%(6)$ \\
Missing & $0 \%(0)$ & \\
\hline
\end{tabular}

${ }^{\mathrm{a} A t}$ follow-up 4 weeks post-operative, no relapse in 1 year.

Table 2. URS complications

\begin{tabular}{clll}
\hline & MCH $(\mathrm{n}=68)$ & Haga $(\mathrm{n}=196)$ & Total $(\mathrm{n}=264)$ \\
\hline $\begin{array}{lll}\text { Complications } \\
\text { Yes }\end{array}$ & $28 \%(19)$ & $22 \%(46)$ & $23 \%(65)$ \\
No & $72 \%(49)$ & $76 \%(146)$ & $75 \%(195)$ \\
Missing & - & $2 \%(4)$ & $2 \%(4)$ \\
Clavien grade & & & \\
0 & $72 \%(49)$ & $76 \%(146)$ & $75 \%(195)$ \\
1 & $19 \%(13)$ & $7 \%(14)$ & $10 \%(27)$ \\
2 & $6 \%(4)$ & $13 \%(25)$ & $11 \%(29)$ \\
$3 \mathrm{a}$ & - & $0.5 \%(1)$ & $0.5 \%(1)$ \\
$3 \mathrm{~b}$ & $3 \%(2)$ & $3 \%(5)$ & $3 \%(7)$ \\
4 & - & - & - \\
5 & - & $0.5 \%(1)$ & $0.5 \%(1)$ \\
\hline
\end{tabular}

ticular medical conditions. The treatment of calculi is one of these subspecialties in urology.

The goal of this study was to provide a clear view of the quality, obtained by URS and PCNL, in 2 hospitals in a major city in the Netherlands. We compared our results with the literature in order to detect possible points of improvement. We discussed technological aspects that could improve the quality and safety of these procedures.

\section{Material and Methods}

The URS and PCNL procedures, performed in Haga Teaching Hospital (Haga) and Medisch Centrum Haaglanden (MCH) during 2010 and 2011 were included in this study. A total of 264 patients were included in the URS database. Of this group, 196 patients were treated in Haga and 68 in MCH. PCNL was performed in 77 patients during the study period, of which 47 were operated in Haga and 30 in $\mathrm{MCH}$.

A database was created in Windows Office Excel 2010 with variables of quality. Patient data were gathered by retrospective viewing of the medical records. The software of IBM SPSS Statistics 20.0 was used to perform statistical analyses. These analyses were individually done for each hospital and were also combined. All outcomes were compared with the literature.

Pearson's chi-squared test was used to assess categorical variables. When analyzing smaller amounts of patients, Fisher's exact test was used. The Mann-Whitney U test was used to compare non-normal distributed variables between 2 groups. Univariate and multivariate logistic regression analysis was performed to show associations between independent categorical variables. When continuous variables were compared with more than 2 groups, the ANOVA test was used with a Bonferroni correction for multiple testing. A P-value of $p<0.05$ was assumed to be statistically significant. The local ethical committee was informed.

\section{Results}

\section{URS}

The average age of the 264 patients (male $=179$, female $=85$ ) included in the URS group was $55 \pm 16$ years. Their average body mass index (BMI) was $27 \pm 4.7 \mathrm{~kg} /$ $\mathrm{m}^{2}$. Most patients $(79 \%)$ suffered from only a single stone. The mean stone diameter (measured by kidney, ureter and bladder) was approximately $9 \mathrm{~mm}(8.9 \pm 4.2$ $\mathrm{mm})$.

Indication for semi-rigid or flexible URS was based on EAU guidelines. A safety wire was introduced in all 
semi-rigid procedures. An access sheet was used for introduction of the flexible ureteroscope. A Holmium laser was applied for defragmentation in the majority of cases. Small fragments were removed using a grasper. Patients were not pre-interventionally stented. The procedure was successful in $69 \%$ of all patients, as intra-operatively estimated by the surgeon. Stones in the distal ureter were most likely to be removed. In Haga a flexible URS for ureteral calculi was significantly more often used (39\%) than in $\mathrm{MCH}(6 \%, \mathrm{p}<0.01)$. Mean operating time (55 minutes) was significantly longer in Haga, than it was in $\mathrm{MCH}$ (35 minutes, $\mathrm{p}<0.01$ ) (table 1).

Complications were more likely to occur when the number of stones to be removed was more than 1 ( $\mathrm{p}=$ 0.04 ). The number of stones varied between 1 and 3, but in 1 case, 4 stones were treated. The number of complications were comparable between the hospitals $(p=0.5)$. The type of complication and its grade, using the Clavien grading system, varied. For example, abrasions or perforation of the ureter/pyelum occurred more often in $\mathrm{MCH}$, whereas in Haga more postoperative infections were observed (table 2). The mean hospitalization time for URS was 3 days. Additional treatment of residual fragments or newly formed calculi was considered to be needed in about 1 of every 3 patients during follow-up. In most cases ESWL or URS was used for retreatment. Stone free status after retreatment has not been evaluated. Sex, age and BMI did not have any influence on quality and outcome of URS.

\section{PCNL}

The mean age was $54 \pm 15.4$ years in the PCNL group. The proportion of male and female patients was 46 and 31 respectively. The average BMI was $27 \pm 4.8 \mathrm{~kg} / \mathrm{m}^{2}$. The average stone diameter was $23 \pm 16.3 \mathrm{~mm}$. Stones were located in the renal pelvis and its different calyces.

The pyelocaliceal system was accessed by a thin needle, using ultrasound and X-ray control. A guide wire was introduced and preceded into the ureter. After this step, the tract was dilated using a balloon dilator. A 30F Amplatz sheath was subsequently placed in situ, through which the scope was inserted.

The procedure was significantly more successful in reaching a stone-free status in Haga (70\%) compared to $\mathrm{MCH}(53 \%)(\mathrm{p}=0.02)$. Operating time was longer when the stone diameter was larger than $20 \mathrm{~mm}(\mathrm{p}=0.03)$ (table 3).

Again there was a difference in type of complication and its Clavien grading (table 4 and 5) between the hospitals. Postoperative bleeding occurred in $\mathrm{MCH}$ in $10 \%$ of patients versus in $2 \%$ in Haga. Blood transfusions were more often necessary in MCH (table 4), but this was not significant. Unlike MCH, Haga preferred to use a nephrostomy tube postoperatively in most cases. The hospitalization time was longer in Haga (5 days), compared to $\mathrm{MCH}$ (4 days, $\mathrm{p}=0.28$ ). Sex, age and BMI did not have any influence on quality and outcome of PCNL.

\section{Discussion}

Average URS operating time in both clinics was comparable to the mean value reported in the literature (1893 minutes) [5, 6]. Flexible URS, in contrast to semi-rigid, was more often performed in Haga. This fact, as well as the larger number of residents performing surgery in this hospital, may be a cause of a longer operating time in Haga [6].

Complication rates of URS were largely the same in both hospitals. Minor lesions of the ureter or pyelum were most frequent, with percentages in the literature ranging from 0 to $15.4 \%$ [7]. In Haga minor lesions of the urinary tract occurred in $2 \%$ and in $\mathrm{MCH}$ in $16 \%$ of the patients. The more frequent use of semi-rigid URS in $\mathrm{MCH}$ may cause this higher percentage. However, the literature does not support this conclusion.

For PCNL there was an important difference between $\mathrm{MCH}$ and Haga. Access to the pyelocaliceal system and the stone site in $\mathrm{MCH}$ was established in the operating theatre, using ultrasound for guidance during puncture. In Haga this procedure was pre-planned, based on CT reconstruction images and access was preoperatively established under ultrasound and fluoroscopy. In $\mathrm{MCH}$, a stone-free status, based on abdominal X-ray (kidney, ureter and bladder) was achieved in 53\% of the cases and in $70 \%$ of the cases in Haga. Preoperative stone load per patient appeared to be similar in both hospitals. Successful PCNL is reported in the literature as ranging from 74 to $92 \%$ [8]. The definition of clinically insignificant residual fragments and stone-free status is often reported differently in publications and may cause confusion in the interpretation of these results $[9,10]$. Average hospital stay in both hospitals was comparable with the literature [11].

Our results support the evidence that both PCNL and URS are treatment options of choice, for aged and/or overweight patients, male or female. Outcome is not influenced by any of these characteristics [12, 13].

Endurance of quality and further improvement of URS and PCNL is demanded by both care providers 
Table 3. PCNL stones removed, postoperative complaints and operating time

\begin{tabular}{llll}
\hline & MCH $(\mathrm{n}=30)$ & Haga $(\mathrm{n}=47)$ & Total $(\mathrm{n}=77)$ \\
\hline Stones removed & & & \\
$\quad$ Yes & $53 \%(16)$ & $70 \%(33)$ & $64 \%(49)$ \\
$\quad$ No & $27 \%(8)$ & $4 \%(2)$ & $13 \%(10)$ \\
$\quad$ Yes, but with residual fragments & $20 \%(6)$ & $26 \%(12)$ & $23 \%(18)$ \\
Free of complaints & $73 \%(22)$ & $67 \%(31)$ & $70 \%(53)$ \\
$\quad$ Yes & $27 \%(8)$ & $33 \%(15)$ & $30 \%(23)$ \\
$\quad$ No & $83(34-143)$ & $77(31-173)$ & $79(31-173)$ \\
Mean operating time minutes (range) & & \\
\hline
\end{tabular}

Table 4. PCNL complications

\begin{tabular}{llll}
\hline & MCH $(\mathrm{n}=30)$ & Haga $(\mathrm{n}=47)$ & Total $(\mathrm{n}=77)$ \\
\hline $\begin{array}{l}\text { Complications }(\mathrm{n}) \\
\text { Clavien grade }\end{array}$ & $30 \%(9)$ & $33 \%(15)$ & $32 \%(24)$ \\
$\quad 1$ & $3 \%(1)$ & $13 \%(6)$ & $9 \%(7)$ \\
2 & $17 \%(5)$ & $9 \%(4)$ & $12 \%(9)$ \\
$3 \mathrm{a}$ & $7 \%(2)$ & - & $3 \%(2)$ \\
$3 \mathrm{~b}$ & $3 \%(1)$ & $11 \%(5)$ & $8 \%(6)$ \\
4 & - & - & - \\
5 & - & - & $8 \%(2)$ \\
Transfusion received $(\mathrm{n})$ & $13 \%(4)$ & & $8 \%(6)$ \\
\hline
\end{tabular}

Table 5. PCNL type of complication

\begin{tabular}{llll}
\hline Type of complication < 30 days & MCH $(\mathrm{n}=30)$ & Haga $(\mathrm{n}=47)$ & Total $(\mathrm{n}=77)$ \\
\hline Fever / infection & $10 \%(3)$ & $9 \%(4)$ & $9 \%(7)$ \\
Postoperative bleeding & $10 \%(3)$ & $2 \%(1)$ & $5 \%(4)$ \\
Parenchymal laceration & - & $13 \%(6)$ & $8 \%(6)$ \\
Readmittance due to pain & $3.3 \%(1)$ & $2 \%(1)$ & $3 \%(2)$ \\
Symptomatic hydronephrosis & $3.3 \%(1)$ & - & $1 \%(1)$ \\
Parenchymal laceration + infection & - & - & $1 \%(1)$ \\
Parenchymal laceration +hydronephrosis & $3.3 \%(1)$ & $5 \%(2)$ & $3 \%(1)$ \\
Re-intervention $<4$ weeks & - & $3 \%(2)$ \\
\hline
\end{tabular}

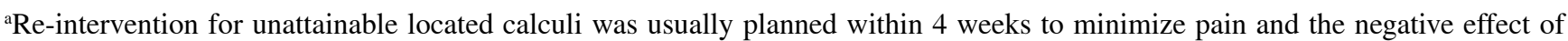
residual calculi and hydronephrosis on kidney function.

Parenchymal laceration: observed intra-operatively by the urologist, defined as a Clavien 1 complication.

(government, doctors and social authorities) and consumers (patients). We investigated the quality of stone care in 2 hospitals.
Our results support that URS, as a treatment for smaller calculi in the urinary tract, can be safely used in both hospitals. It is clear that a single simple stone in the distal 
ureter can be treated by all urologists practising endourology. However, flexible URS and PCNL are also used as a treatment modality for larger and more complex stones in the upper urinary tract. These more complex treatments need a precautionary plan.

Knowledge of renal anatomy is of utmost importance in order to find and eliminate calculi. When preplanning URS or PCNL, these anatomical data need to be applied and personalized for the renal anatomy of individual patients in order to provide optimal surgical information for the urologist. In our PCNL group, 90\% were evaluated using CT abdomen in order to establish optimal anatomical data pre-operatively.

Rigid PCNL is limited in its maneuvers in the curved pyelocalycial system and a flexible URS is often unstable in the ureter. Optimization of technical aspects and instruments can provide better outcome of minimally invasive procedures. For example, a (short) flexible renoscope can be used for PCNL to facilitate sight and operative maneuvers in order to work around narrower angles. Another example is a thinner flexible URS, is able to pass any narrow points in the ureter.

When it comes to large, hard stones or those situated in an unattainable position, we believe that centralization and sub-specialization will improve quality of minimally invasive procedures. The two hospitals discussed in our quality analysis have decided to refer and to treat more difficult cases in Haga.

\section{Conclusion}

The success rate of URS in both clinics and PCNL in Haga concur with those reported in the literature. Complication rates, operating and hospitalization time correspond with the literature for both procedures and clinics. Outcome and quality of PCNL and URS is not influenced by sex, age or BMI. Further improvement in minimally invasive surgery for renal and ureteric calculi is feasible and can be made by optimization of technical aspects and knowledge of renal anatomy. Also, sub-specialization and centralization in the treatment and care of urolithiasis is mandatory. A study group has been initiated with a main focus on stone pathology, technical aspects of minimally invasive surgery, and improvement of care in urolithiasis.

\section{References}

1 Robertson WG, Peacock M, Baker M, Marshall DH, Pearlman B, Speed R, Sergeant V, Smith A: Studies on the prevalence and epidemiology of urinary stone disease in men in Leeds. Br J Urol 1983;55:595-598.

2 Türk C, Knoll T, Petrik A, Sarica K, Seitz C,Straub M: Guidelines on urolithiasis. www. uroweb.org/gls/pockets/english/22_Urolithiasis.pdf , EAU 2012.

-3 Preminger GM, Tiselius HG, Assimos DG, Alken P, Buck AC, Gallucci M, Knoll T, Lingeman JE, Nakada SY, Pearle MS, Sarica K, Türk C, Wolf JS Jr: 2007 Guideline for the management of ureteral calculi. Eur Urol 2007;52:1610-1631.

4 Hundepool S, van der Kamp B: Vergelijkingssite als kwaliteitsinstrument. Online Source. 2011.

5 Degirmenci T, Gunlusoy B, Kozacioglu Z, Arslan M, Kara C, Koras O, Minareci S: Outcomes of ureteroscopy for the management of impacted ureteral calculi with different localizations. Urology 2012;80:811-815.
6 Atis G, Gurbuz C, Arikan O, Canat L, Kilic M, Caskurlu T: Ureteroscopic management with laser lithotripsy of renal pelvic stones. J Endourol 2012;26:983-987.

7 D'Addessi A, Bassi P: Ureterorenoscopy: avoiding and managing the complications. Urol Int 2011;87:251-259.

$\checkmark 8$ Abdelhafez MF, Bedke J, Amend B, ElGanainy E, Aboulella $\mathrm{H}$, Elakkad M, Nagele U, Stenzl A, Schilling D: Minimally invasive percutaneous nephrolitholapaxy (PCNL) as an effective and safe procedure for large renal stones. BJU Int 2012;110:E1022-1026.

$\checkmark 9$ Deters LA, Jumper CM, Steinberg PL, Pais VM Jr: Evaluating the definition of "stone free status" in contemporary urologic literature. Clin Nephrol 2011;76:354-357.

10 Cicerello E, Merlo F, Maccatrozzo L: Management of clinically insignificant residual fragments following shock wave lithotripsy. Adv Urol 2012;2012:320104.
1 Cormio L, Gonzalez GI, Tolley D, Sofer M, Muslumanoglu A, Klingler HC, Stolzenburg JU, de la Rosette J: Exit strategies following percutaneous nephrolithotomy (PCNL): a comparison of surgical outcomes in the Clinical Research Office of the Endourological Society (CROES) PCNL Global Study. World J Urol 2012;31:1239-1244.

12 El-Assmy AM, Shokeir AA, El-Nahas AR, Shoma AM, Eraky I, El-Kenawy MR, El-Kappany HA: Outcome of percutaneous nephrolithotomy: effect of body mass index. Eur Urol 2007;52:199-204.

-13 Doré $\mathrm{B}$, Conort $\mathrm{P}$, Irani J, Amiel J, Ferrière JM, Glémain P, Hubert J, Lechevallier E, Meria P, Saussine C, Traxer O: Percutaneous nephrolithotomy (PCNL) in subjects over the age of 70: a multicentre retrospective study of 210 cases. Prog urol 2004;14:1140-1145. 